\title{
Determinants of drug-related problems among ambulatory type 2 diabetes patients with hypertension comorbidity in Southwest Ethiopia: a prospective cross sectional study
} CrossMark

Mohammed Yimama ${ }^{1}$, Habtemu Jarso ${ }^{2}$ and Tigestu Alemu Desse ${ }^{3 *}$

\begin{abstract}
Objective: The aim of this study was to assess drug-related problems and its determinants in type 2 diabetes patients with hypertension co-morbidity.

Results: A total of 300 type 2 diabetes patients with hypertension co-morbidity were studied. The majority of participants, 194 (64.7\%), were males. Mean age of the participants was $54.44 \pm 11.68$ years. The mean durations of diabetes and hypertension were $5.37 \pm 4.79$ and $5.15 \pm 4.65$ years respectively. The most commonly prescribed antidiabetic medications were metformin in 200 (66.7\%) and insulin 126 (42\%) of the participants. Enalapril was the most commonly prescribed antihypertensive medication; 272 (90.7\%). Aspirin was prescribed to 182 (60.7\%) participants. Statins were prescribed to one-third (65.67\%) of the participants. Eighty-five (28.3\%) participants had diabetes related complications other than hypertension. A total of 494 drug related problems were identified. The mean number of drug related problems was $1.65 \pm 1.05$. The most common drug related problems were need for additional drug therapy (29.35\%), ineffective drug (27.94\%) and dose too low (15.8\%). Independent predictors of drug related problems were age $41-60$ years $(A O R=6.87,95 \% \mathrm{Cl} 2.63-17.93)$, age $>60$ years $(A O R=5.85,95 \% \mathrm{Cl} 2.15-15.93)$ and the presence of comorbidity (AOR $=3.0,95 \% \mathrm{Cl} 1.11-8.16)$.
\end{abstract}

Keywords: Type 2 diabetes, Hypertension, Drug-related problems, Ethiopia

\section{Introduction}

Uncontrolled diabetes is the major cause of microvascular and microvascular complications [1-4] and death [5, 6]. The presence of hypertension with diabetes increases risk of mortality by 7.2 fold [7-9] with a greater risk of death in developing nations [10].

Achieving target blood glucose in type 2 diabetes patients with hypertension remains a big challenge despite the availability of different classes of drugs [11]. Studies show that about two-third of type 2 diabetes patients with hypertension fail to achieve target blood

\footnotetext{
*Correspondence: tgfrekidan16@gmail.com; tigestu.alemu@aau.edu.et ${ }^{3}$ Department of Pharmacology and Clinical Pharmacy, School of Pharmacy, College of Health Sciences, Addis Ababa University, Addis Ababa, Ethiopia

Full list of author information is available at the end of the article
}

glucose and blood pressure [12, 13]. A study in Canada on type 2 diabetes patients with hypertension revealed that $70 \%$ of patients receiving mono-therapy did not achieve target blood pressure (BP) whereas the level of uncontrolled BP in patients receiving dual, triple, and 4 medications was 65,66 , and $46 \%$ respectively [14].

Multiple medical conditions have been shown to contribute to drug related problems (DRPs) [15-19]. Similarly, type 2 diabetes patients with hypertension often use multiple medications and this may lead to the occurrence of drug related problems [11, 20,21]. Studies show that the number of DRPs per patient linearly increases with the increase in the number of drugs used [22-25].

Drug related problems may lead to increased morbidity, mortality, healthcare costs, and recurrent hospital admissions and prolonged hospitalization [26]. Cost of 
drug-related problem related morbidity and mortality exceeds the cost of the medications themselves [27].

In Ethiopia [28] hypertension is the common comorbidity in type 2 diabetes patients. Despite the high prevalence of type 2 diabetes with hypertension and drug treatment related problems, no adequate studies have been conducted in the country. Therefore, this study aimed to investigate the magnitude of DRPS and contributing factors in type 2 diabetes patients with hypertension in a resource limited setting.

\section{Main text}

\section{Research methods and patients}

This was a prospective cross sectional study among type 2 diabetes patients with hypertension comorbidity at Jimma University Specialized Hospital (JUSH) from April 4 to May 11, 2016. The hospital is the only teaching and referral hospital in Southwestern part of Ethiopia. It provides specialized health services for approximately 15,000 inpatient, 160,000 outpatient attendants a year [29]. The hospital ambulatory care clinic serves for 1700 type 2 diabetes and 2017 hypertensive patients. Patients with diabetes and hypertension have regular follow up every month with possible extension to every 3 months for some patients.

The study was approved by institutional review board of Jimma University. We obtained written informed consent from study participants. Sample size was calculated using a single proportion formula with the assumption of 5\% margin of error, $95 \%$ confidence interval and $50 \%$ prevalence of drug related problems (DRPs) in type 2 diabetes patients with hypertension. Through calculation, the total sample size was 309. All type 2 diabetes patients with hypertension who fulfilled the inclusion criteria and who visited diabetes clinic during the study period were included. To ensure the quality of the data; we gave training to data collectors and English version of the data collection questionnaire was translated to Afan Oromo and Amharic and back translated to English. The data collection tool was also pretested. The main outcome of this study was the presence of drug related problems among type 2 diabetes patients with hypertension co-morbidity.

We included patients: age $\geq 18$ years old, type 2 diabetes with hypertension, and patients on treatment with anti-diabetic and anti-hypertensive medications for at least 6 months. Participants not willing to participate, with psychiatric comorbidity, and with incomplete medical records were excluded from the study.

We used data abstraction format to collect data on diagnosis, duration of illness, dosage regimen, adverse drug reactions (ADRs), diabetes complications, blood glucose and blood pressure measurements, and laboratory results. Structured questionnaire was used to collect patients' demographics, and patients' medication experience. Patients whith evidence of circumstances or events related to drug therapy that actually or potentially interfere with desired health outcomes were considered to have DRP. Drug related problems (DRPs) and possible causes of DRPs were identified using Cipolle's drug related problem identification tool $[8,15]$ pharmacotherapy text book and Ethiopian standard treatment guideline [30, 31]. Naranjo Adverse Drug Reaction Probability Scale [32] was to identify ADRs. Adverse Drug Reaction Probability Scale was categorized by taking sum of 10 questions and grouped as definite, probable, possible or doubtful, if the total score is $>9,5-8,1-4$ and 0 respectively.

Data were collected by trained data collectors (two Pharmacists and one nurse). The data abstracted from patient charts were: diagnoses, comorbidities, dosage regimen, diabetes related complications, laboratory tests, blood glucose and blood pressure measurements of the last three consecutive months.

\section{Statistical analysis}

Data were analyzed using SPSS Version 21.0 (Chicago, SPSS Inc.). We performed univariate logistic regression tests to assess the association between independent variables and dug related problems (DRPs). Variables with $\mathrm{P}<0.25$ on a univariate analysis were entered into a multivariable analysis to identify independent predictors of DRPS. Statistical significance was declared for variables with $\mathrm{P} \leq 0.05$.

\section{Operational definitions and definition of terms}

Adverse drug reaction: any response to a drug which is noxious and unintended and that occurs at normal therapeutic dose [33].

Dosage regimen: dose of the medication, frequency of administration, and duration of treatment [3].

Comorbidity: the presence of additional diseases in relation to an index disease [34].

Drug-related problems: events or circumstances involving drug therapy that actually or potentially interfere with desired health outcomes [25].

Renal impairment: the presence of chronic kidney disease, chronic interstitial nephritis, chronic glomerulonephritis, creatinine clearance of less than $50 \mathrm{~mL} /$ min, or diabetic nephropathy [35].

Poly-pharmacy: consumption of five or more medications [19].

Concomitant medications: drugs in which their indications are neither hypertension nor diabetes [36]. 


\section{Results}

\section{Characteristics of participants}

Out of 309 participants, 300 (97.08\%) of them fulfilled the inclusion criteria and were included in the study. The mean age of the participants was $54.44 \pm 11.68$ years (range 22-90 years). One hundred ninety-four (64.7\%) participants were males. The majority, $87.3 \%$, of the participants were married, $7.67 \%$ widowed and $5 \%$ divorced. One hundred twenty-six (42\%) of the participants were illiterate and over one-third of the participants (34\%) were farmers. The mean duration of diabetes was $5.4 \pm 4.8$ years. The mean duration of hypertension was $5.2 \pm 4.7$ years. Most of the study participants were diagnosed in the last 5 years.

Seventy (23.3\%) participants had at least one co-morbidity. Peptic ulcer disease; 28 (40.00\%) and congestive heart failure; 19 (27.14\%) were the most common comorbidities. Eighty-five (28.33\%) participants had at least one diabetes related complication. Neuropathy was the most common microvascular type 2 diabetes complication; 43 (50.59\%) followed by retinopathy; 27 (31.77\%).

\section{Prescribed Medications}

The mean number of prescribed medications was $4.08 \pm 1.15$ ranging from 2 to 10 medications per patient (Table 1). One hundred and two (34\%) of the participants were taking $\geq 5$ Medications. Nearly two-third (63.0\%) of the participants was on diabetes monotherapy. Metformin was the most common prescribed anti-diabetic medication as monotherapy; 89 (29.67\%), followed by insulin; 79 (26.33\%). The most common combination therapy was a combination of metformin and glibenclamide; 74 (24.67\%).

Enalapril was the most frequently used antihypertensive medication; 237 (79.0\%). Hydrochlorothiazide was prescribed for 17 (5.67\%) of the participants. A combination of enalapril and amlodipine were most commonly used antihypertensive medications; 22 (7.33\%). Aspirin, $182(60.67 \%)$, and Simvastatin, 85 (28.33\%), were the most commonly prescribed medications to prevent cardiovascular comorbidities. Thirty-two (10.67\%) participants were using omeprazole.

\section{Drug related problems and predictors of drug related problems}

A total number of 494 drug related problems (DRPs) were identified. The mean number of DRPs was $1.65 \pm 1.05$ (Table 2). The majority (82\%) of the participants had at least one DRP. One hundred twenty-one (40.3\%) of the participants had two drug related problems. Most common DRP was noted in participants $41-60$ years. Need for additional drug therapy was the most common
Table 1 Medications prescribed to diabetes patients with hypertension at Jimma University Specialized Hospital

\begin{tabular}{|c|c|}
\hline Variable category & Frequency (\%) \\
\hline \multicolumn{2}{|l|}{ Number of medications } \\
\hline$<5$ & $198(66.00)$ \\
\hline$\geq 5$ & $102(34.00)$ \\
\hline \multicolumn{2}{|l|}{ Type of medication } \\
\hline Metformin & $89(29.67)$ \\
\hline Insulin & $79(26.33)$ \\
\hline Glibenclamide & $11(3.67)$ \\
\hline Aspirin & $182(60.67)$ \\
\hline Lovastatin & $84(28.00)$ \\
\hline Simvastatin & $85(28.33)$ \\
\hline Atorvastatin & $28(9.33)$ \\
\hline Enalapril & $237(79.00)$ \\
\hline Hydrochlorothiazide & $17(5.67)$ \\
\hline Amlodipine & $5(1.67)$ \\
\hline Atenolol & $16(5.33)$ \\
\hline Amytriptyline & $31(10.33)$ \\
\hline Omeprazole & $32(10.67)$ \\
\hline Furosemide & $8(2.67)$ \\
\hline Others* & $13(4.33)$ \\
\hline \multicolumn{2}{|l|}{ Combined anti-diabetic medications } \\
\hline Metformin + glibenclamide & $74(24.67)$ \\
\hline Metformin + insulin & $37(12.33)$ \\
\hline Glibenclamide + insulin & $7(2.33)$ \\
\hline Metformin + glibenclamide + insulin & $3(1.00)$ \\
\hline \multicolumn{2}{|l|}{ Combined anti-hypertensive medications } \\
\hline Enalapril + amlodipine & $22(7.33)$ \\
\hline Enalapril + hydrochlorothiazide & $13(4.33)$ \\
\hline Hydrochlorothiazide + amlodipine & $2(.67)$ \\
\hline
\end{tabular}

*Metoprolol, Salbutamol, Alfuzosin, Carbamazepine, Ranitidine

drug related problem; $29.35 \%$ followed by ineffective drug therapy; (27.94\%) and dose too low; (15.80\%). On adjusted bi-variable logistic regression analysis, independent predictors of drug related problem were age 41-60 years, age $>60$ years and the presence of comorbidity (Table 3 ).

\section{Discussion}

Our study revealed that $82 \%$ of the participants had at least one drug related problem. The mean number of drug related problems was $1.65 \pm 1.05$ per patient. The most common drug related problems were need for additional drug therapy (29.35\%), ineffective drug therapy (27.94\%) and dose too low (15.8\%).

The finding in our set up that $82 \%$ of the participants had at least one DRP is comparable with the report by Haugbolle et al. [37] where $80.7 \%$ of patients had at least 
Table 2 Drug related problems and causes in type 2 diabetes patients with hypertension

\begin{tabular}{|c|c|}
\hline Variable category & $\begin{array}{l}\text { Frequency } \\
\text { (\%) }\end{array}$ \\
\hline \multicolumn{2}{|l|}{ Number of DRPs } \\
\hline One & $64(21.3)$ \\
\hline Two & $121(40.3)$ \\
\hline Three & $55(18.3)$ \\
\hline Four & $6(2.0)$ \\
\hline \multicolumn{2}{|l|}{ Category of DRP and its causes } \\
\hline Need for additional drug therapy & $145(29.4)$ \\
\hline Medical condition requires the initiation of drug therapy & $4(2.8)$ \\
\hline $\begin{array}{l}\text { Preventive drug therapy required to reduce the risk of } \\
\text { developing a new condition }\end{array}$ & $124(85.5)$ \\
\hline $\begin{array}{l}\text { Medical condition requires additional pharmacotherapy } \\
\text { to attain synergistic or additive effects }\end{array}$ & $12(8.3)$ \\
\hline $\begin{array}{l}\text { Required preventive drug therapy to reduce the risk of } \\
\text { developing a new condition \& a medical condition } \\
\text { requires additional pharmacotherapy to attain syner- } \\
\text { gistic or additive effects }\end{array}$ & $5(3.4)$ \\
\hline Ineffective drug & $138(27.9)$ \\
\hline $\begin{array}{l}\text { The drug not the most effective for the medical prob- } \\
\text { lem }\end{array}$ & $114(82.6)$ \\
\hline $\begin{array}{l}\text { The drug product is not effective for the indication } \\
\text { being treated }\end{array}$ & $24(17.4)$ \\
\hline Dosage too low & $78(15.8)$ \\
\hline The dose is too low to produce the desired response & $76(97.4)$ \\
\hline $\begin{array}{l}\text { Drug interaction reduces the amount of active drug avail- } \\
\text { able }\end{array}$ & $2(2.6)$ \\
\hline Noncompliance & $60(12.2)$ \\
\hline The patient prefers not to take the medication & $6(10.0)$ \\
\hline The patient forgets to take the medication & $27(45.0)$ \\
\hline The drug product too expensive for the patient & $3(5.0)$ \\
\hline $\begin{array}{l}\text { The patient prefers not to take the medication \& the } \\
\text { patient forgets to take the medication }\end{array}$ & $17(28.3)$ \\
\hline $\begin{array}{l}\text { The patient forgets to take the medication \& the drug } \\
\text { product too expensive for the patient }\end{array}$ & $5(8.3)$ \\
\hline $\begin{array}{l}\text { The patient prefers not to take the medication, the drug } \\
\text { product too expensive for the patient \& the patient } \\
\text { forgets to take the medication }\end{array}$ & $2(3.3)$ \\
\hline Unnecessary drug therapy & $51(10.3)$ \\
\hline No valid medical indication for the drug & $45(88.2)$ \\
\hline $\begin{array}{l}\text { Multiple drug products are being used for a condition } \\
\text { that requires single drug therapy }\end{array}$ & $4(7.8)$ \\
\hline $\begin{array}{l}\text { No valid medical indication for the drug \& multiple drug } \\
\text { products are being used for a condition that requires } \\
\text { single drug therapy }\end{array}$ & $2(3.9)$ \\
\hline Adverse drug reaction & $13(2.6)$ \\
\hline $\begin{array}{l}\text { The drug product causes an undesirable reaction that is } \\
\text { not dose-related }\end{array}$ & $7(53.9)$ \\
\hline The drug product contraindicated due to risk factors & $6(46.2)$ \\
\hline Dosage too high & $9(1.8)$ \\
\hline Dose too high & $7(77.8)$ \\
\hline $\begin{array}{l}\text { A drug interaction occurs resulting in a toxic reaction to } \\
\text { the drug product }\end{array}$ & $2(22.2)$ \\
\hline
\end{tabular}

one drug related problem. Similar findings were reported in Adama, Ethiopia [38]. The rate of DRPs in our set up is higher than the findings from India [39] where $71.1 \%$ of the patients had at least one drug related problem (mean $1.30 \pm 1.10$ ). The higher level of DRPS in our set up may be attributed to the difference in the study populations between ours and the Indians. For example, in the Indian study, all the studied patients did not have hypertension comorbidity. The difference in the study design (prospective interventional study design in Indian Study) and level of care given to diabetes patients might also have contributed for this variation.

The rate of DRP in our study is lower than the findings in Malaysia [19]. This discrepancy might be due to differences in the tool used to assess DRPS and different classification systems of DRPS. For instance, insufficient awareness of health and diseases (22\% of all the cases) was considered as DRP in Malay study. In addition, subject variability and difference in level of care given might have contributed for this disparity. In our study, $42.0 \%$ of participants were illiterate and patients are often given care by medical interns.

Need for additional drug therapy (29.35\%) and ineffective drug therapy (27.94\%) were the most common drug related problems observed in our study. The majority $(71 \%)$ need for statin therapy. Our report is higher than the reports from Malaysia [19], India and Indonesia ([18, 40] which ranged from 4.5 to $15.61 \%$. These variations may be attributed to differences in the tools used to classify drug related problems and study designs. Pharmaceutical Care Network Europe classification of DRPs was used to categorize DRPs in other studies while we used Cipoll's drug related problem identification tool in our study. Differences in type 2 diabetes management and the study settings might also be the possible reasons. For example, nearly $10 \%$ of type 2 diabetes patients with hypertension comorbidity in our set up received Hydrochlorothiazide or Amilodipine while guidelines recommend the use of angiotensin converting enzyme inhibitors, angiotensin receptor blockers or nondihydropyridine clacium channel blockers [41]. The rate of ineffective drug therapy in our study is lower than the study in Indonesia [42] where ineffective drug therapy was identified in $50 \%$ of the participants.

Dose too low constituted $15.80 \%$ of the total drug related DRPs. This was in line with the study in Thailand [43] and Ambo [44], Ethiopia, but higher than the reports from Malaysia, Indonesia and India; range from 1.3 to $12.92 \%$ [16, 33, 34]. This discrepancy may be due to the fact that all of the studies were done in hospitalized patients where there may be better care and nurse supervised medication administration. Differences in 
Table 3 Predictors of drug related problems in type 2 diabetes patients with hypertension

\begin{tabular}{llll}
\hline Variable category & DRP & COR $(95 \% \mathrm{Cl})$ & AOR $(95 \% \mathrm{Cl})$ \\
\cline { 2 - 3 } & Yes No & \\
\hline
\end{tabular}

\begin{tabular}{|c|c|c|c|c|}
\hline \multicolumn{5}{|c|}{ Age in years } \\
\hline $21-40$ & 13 & 14 & 1 & 1 \\
\hline $41-60$ & 140 & 21 & $7.2(2.97-17.4)$ & $6.54(2.58-16.61)^{*}$ \\
\hline$>60$ & 93 & 19 & $5.27(2.14-13.00)$ & $5.1(1.95-13.3)^{*}$ \\
\hline \multicolumn{5}{|c|}{ Duration of DM in years } \\
\hline$\leq 5$ & 170 & 31 & 1 & 1 \\
\hline $6-10$ & 49 & 12 & $0.75(0.36-1.56)$ & $0.87(0.36-2.1)$ \\
\hline$\geq 11$ & 27 & 11 & $0.45(0.20-0.9)$ & $0.59(0.2-1.8)$ \\
\hline \multicolumn{5}{|c|}{ Duration of HTN in years } \\
\hline$\leq 5$ & 180 & 32 & 1 & 1 \\
\hline $6-10$ & 44 & 13 & $0.60(0.3-1.2)$ & $0.7(0.28-1.65)$ \\
\hline$\geq 11$ & 22 & 9 & $0.44(0.18-1.03)$ & $0.60(0.19-1.1)$ \\
\hline \multicolumn{5}{|c|}{ Comorbid disease } \\
\hline Yes & 65 & 5 & $3.52(1.34-9.22)$ & $3.01(1.11-8.16)^{*}$ \\
\hline No & 182 & 48 & & 1 \\
\hline
\end{tabular}

* Statistically Significant

DM diabetes mellitus, HTN hypertension, COR crude odds ratio, AOR adjusted odds ratio

classification systems of DRPs may also contribute to such difference.

Noncompliance to medications contributed to $12.15 \%$ of the total DRPS. Our result was comparable to Malay [19], but lower than Indian [18] and Nigerian findings [45]. The reason for lower or comparable level of noncompliance in our study is unjustifiable. Unnecessary drug therapy constituted $10.32 \%$ of all DRPs. This is higher than the Malay [19] finding, but lower than the Indonesian finding [42]. This may be due to differences in DRP assessment tools, study settings and patient characteristics.

Adverse drug reaction and dosage too high were less frequently occurring DRPs in this study. Age 41-60 years, age $>60$ years and the presence of comorbidity were independent predictors of drug related problems.

\section{Conclusions}

The rate of drug related problems in type 2 diabetes patients with hypertension is high. The most common DRPs were need for additional drug therapy, ineffective drug therapy and dose too low. The most common causes of DRPs were need for preventive drug therapy and the drug not the most effective for the medical problem. Age 41-60 years, age $>60$ years and the presence of comorbidity were independent predictors of drug related problems.

\section{Limitations}

The limitation of this study was the small sample size to generalize the findings to the general population.

\section{Abbreviations}

DRPs: drug related problems; T 2 DM: type two diabetes mellitus; COR: crude odds ratio; AOR: adjusted odds ratio; JUSH: Jimma University Specialized Hospital; ADR: adverse drug reaction.

\section{Authors' contributions}

MY involved in the conception and design of the study, developed data collection tools, supervised data collection and involved in data analysis. $\mathrm{HJ}$ involved in the design of the study, supervised data collection and the overall research, involved in data analysis and commented the manuscript. TAD involved in the conception and design of the study, developed data collection tools, supervised data collection and the overall research, analyzed data and wrote the manuscript. All authors read and approved the final manuscript.

\section{Author details \\ 1 Department of Pharmacy, College of Health Sciences, Mizan Tepi University, Mizan, Ethiopia. ${ }^{2}$ Department of Epidemiology, College of Health Sciences, Jimma University, Jimma, Ethiopia. ${ }^{3}$ Department of Pharmacology and Clini- cal Pharmacy, School of Pharmacy, College of Health Sciences, Addis Ababa University, Addis Ababa, Ethiopia.}

\section{Acknowledgements}

We would like to acknowledge the study participants for their consent and patience during data collection. We would also like to thank Jimma University for financing this study.

\section{Competing interests}

The authors declare that they have no competing interests.

\section{Availability of data and materials}

The supporting documents for this study can be available from the corresponding author upon request.

\section{Consent for publication}

Not applicable.

\section{Ethics approval and consent to participate}

The study was approved by Institutional Review Board of Jimma University and we obtained a written informed consent from patients to participate in this study.

Funding

Not applicable.

\section{Publisher's Note}

Springer Nature remains neutral with regard to jurisdictional claims in published maps and institutional affiliations.

Received: 10 Auqust 2018 Accepted: 20 September 2018

Published online: 24 September 2018

\section{References}

1. World Health Organization. Definition, diagnosis and classification of diabetes mellitus and its complications report of WHO consultation part 1. Geneva: World Health Organization; 1999. p. 1-59.

2. Chidambaram D, Sumy S, AKKS. Role of clinical pharmacist in the management of type II diabetes mellitus and its outcomes. Int J Pharm Teach Pract. 2014;5(3):977-83.

3. Cipolle RJ, Strand LM, Frakes MJ. Co-morbidities and Drug Therapy Problems in Patients with Diabetes. Medication Management Systems, Inc. 2013. 
4. Feher MD. Hypertension in non-insulin dependent diabetes mellitus and its management. Postgr Med J. 1991;67:938-46.

5. American Diabetes Association. Standards of medical care. Diabetes Care. 2015;38(Supplement):1.

6. Amanda N, Long D, Dagogo-Jack S. The comorbidities of diabetes and hypertension: mechanisms and approach to target organ protection. J Clin Hypertens (Greenwich). 2011:13(4):244-51.

7. National Diabetes Education Program. The Link between diabetes and cardiovascular disease. 2007.

8. George L, Bakris JR. Treatment of hypertension in patients with diabetes. J Clin Hypertens. 2008;10(9):707-13.

9. Paul A, James SO. Evidence-based guideline for the management of high blood pressure in adults: report from the panel members appointed to the Eighth Joint National Committee (JNC 8). JAMA. 2014;311(5):507-20. https://doi.org/10.1001/jama.2013.284427.

10. Awoke A, Awoke T, Alemu S, Megabiaw B. Prevalence and associated factors of hypertension among adults in Gondar, Northwest Ethiopia: a community based cross-sectional study. BMC Cardiovasc Disord. 2012;12:2-7.

11. Munger MA. Polypharmacy and combination therapy in the management of hypertension in elderly patients with co-morbid diabetes mellitus. Drugs Aging. 2010;27(11):871-83.

12. Allender S, Peto V, Scarborough P, Kaur A, Rayner M. Coronary heart disease statistics. London: British Heart Foundation; 2008.

13. Ong KL, Cheung BM, Man YB, Lau CP, Lam KS. Prevalence, awareness, treatment, and control of hypertension among United States adults 1999-2004. Hypertension. 2007:49(1):69-75.

14. Supina AL, Guirguis LM, Majumdar SR, Lewanczuk RZ, Lee TK, Ellen L, Toth AJ. Treatment gaps for hypertension management in rural canadian patients with type 2 diabetes mellitus. Clin Ther. 2004;26(4):598.

15. Blix HS, Viktil KK, Reikvam A, Moger TA, Hjemaas BJ, Pretsch P, Vraalsen TFWE. The majority of hospitalised patients have drug-related problems: results from a prospective study in general hospitals. Eur J Clic Pharmacol. 2004;60(9):651-8

16. Hajjar ER, Hanlon JT, Artz MB, Lindblad Cl, Pieper CF, Sloane RJ, Ruby CMSK. Adverse drug reaction risk factors in older outpatients. Am J Geriatr Pharmacother. 2003;1 (2):82-9.

17. Cipolle RJ, Strand LM, Morley PC. Pharmaceutical care practice. 2nd ed. New York: McGraw-Hill; 1998.

18. Gangwar SS, Parimalakrishnan S, Monisha N, Singh SP. Impact of medication and psychological behavior assessment by community pharmacists in type 2 diabetes mellitus patients after hospital stay. Int Res J Pharm. 2014;5(4):332-9.

19. Huri HZ, Wee HF. Drug related problems in type 2 diabetes patients with hypertension: a cross-sectional retrospective study. BMC Endocr Disord. 2013;13(1):2.

20. Grant RW, Devita NG, Daniel E, Singer JB. Polypharmacy and medication adherence in patients with type 2. Diabetes Care. 2003;26:1408-12.

21. Rahmawati F, Pramantara IDP, Rohmah W, Azhar S, Sulaiman S. Polypharmacy and unnecessary drug therapy on geriatric. Int J Pharm Pharm Sci. 2009;1:6-11.

22. Viktil KK, Blix HS, Moger TA, Reikvam A. Polypharmacy as commonly defined is an indicator of limited value in the assessment of drug-related problems. Br J Clin Pharmacol. 2007;63(2):187-95.

23. van Bob W, van Krass I. Development of an evidence-based checklist for the detection of drug related problems in type 2 diabetes. Pharm World Sci. 2009;31(5):580-95.

24. Anne JL, Antoine CGE, Lennart JS, van den Bemt PM. Frequency of and risk factors for preventable medication-Related Hospital Admissions in the Netherlands. Arch Intern Med. 2010;168(17):1890-6.

25. Pharmaceutical Care Network Europe Foundation: PCNE classification for drug-related problems V5.01. 2006. http://www.pcne.org/sig/drp/docum ents/.
26. Linda T, Kohn JM, Corrigan A, Donaldson MS. To Err is human building a safer health system. New York: National Academy Press; 1999. p. 1-34.

27. Frank RE, Grizzle AJ. Drug-related morbidity and mortality in US. J Am Pharm Assoc. 2001;41(2):192.

28. Wabe NT, Angamo MT, Hussein S. Medication adherence in diabetes mellitus and self management practices among type-2 diabetics in Ethiopia. N Am J Med Sci. 2011:3(9):5-10.

29. Jimma University; https://www.ju.edu.et/.

30. Cipolle RJ, Strand LM, Morley PC. Pharmaceutical care. 2nd ed. London: McGraw-Hill; 1998.

31. Joseph TD, Robert LT, Gary CY, Gary RM, Barbara GW. Pharmacotherapy: a pathophysiologic approach. Ninth. 2014.

32. Naranjo CA, Busto U, Sellers EM, Sandor P, Ruiz I, Roberts EA, et al. A method for estimating the probability of adverse drug reactions. Clin Pharmacol Ther. 1981;30:239-45.

33. WHO. WHO meeting on international drug monitoring: the role of national centers. Geneva: WHO; 1972.

34. Chin YR, Lee IS, Lee HY. Effects of hypertension, diabetes, and/o cardiovascular disease on health-related quality of life in elderly korean individuals: a population-based cross-sectional survey. Asian Nurs Res. 2014;8(4):267-73.

35. Maegan R. Sulfonylurea-induced hypoglycemia : the case against glyburide. New York: ConsultantLive; 2011. p. 1-4.

36. Eric S. Documenting concomitant medications in clinical trials. J Clin Res Best Pract. 2007;3(7):3-7.

37. Haugbolle LSSE. Drug-related problems in patients with angina pectoris, type 2 diabetes and asthma. Pharm World Sci. 2006;28(4):239-47.

38. Hussein M, Lenjisa JL, Woldu MA, Tegegne GT, Umeta GT, Dins H. Assessment of drug related problems among hypertensive patients on follow up in Adama Hospital Medical College, East Ethiopia. Clin Pharmacol Biopharm. 2014:3(2):2-7.

39. Javedh S, Fernandes J, Samaga L. Clinical pharmacist interventions in drug therapy in patients with diabetes mellitus and hypertension in a University Teaching Hospital. Int J Pharm Sci Res. 2015;6(10):4424-32.

40. Ogbonna BO, Ezenduka CC, Opara CA. Drug therapy problems in patients with type-2 diabetes in a Tertiary Hospital in Nigeria Abstract. Int J Innov Res Dev. 2014;3(1):494-502.

41. Dennison-himmelfarb C, Handler J, Lackland DT. Evidence-based quideline for the management of high blood pressure in adults report from the panel members appointed to the eighth joint national committee (JNC 8). JAMA. 2014;1097(5):507-20.

42. Utara Universitas Sumatera. Identification of drug related problems in patients type 2 diabetes mellitus with complication of hypertension at General Hospital Inpatient Langsa. 2011;61-2.

43. Azizah N, Khairunnisa HR. Drug therapy problems in management of hypertensive outpatients admitted to four Indonesian Primary Health Centers. Asian J Pharm. Clin Res. 2016;9(1):87-9.

44. Tegegne GT, Gaddisa T, Kefale B, Tesfaye G, Likisa J, Albachew M, et al. Drug therapy problem and contributing factors among ambulatory hypertensive patients in ambo General Hospital, West Shoa, Ethiopia. Glob J Med Res B Pharma Drug Discov Toxicol Med. 2015;15(4)20-26.

45. Eze Uchenna IH. Evaluation of drug use among diabetic hypertensive patients. Int J Drug Dev Res. 2010;2:703-10.

Ready to submit your research? Choose BMC and benefit from:

- fast, convenient online submission

- thorough peer review by experienced researchers in your field

- rapid publication on acceptance

- support for research data, including large and complex data types

- gold Open Access which fosters wider collaboration and increased citations

- maximum visibility for your research: over 100M website views per year

At BMC, research is always in progress.

Learn more biomedcentral.com/submissions 